\title{
Adenosine Triphosphate (ATP)-Stabilized Gold Nanoparticle Based-colorimetric Acetylcholinesterase Assay Method with High Signal/Noise Ratio in End-point Analysis
}

\author{
Min Sik Eom, Sudeok Kim, Sujung Yi, Seok Keun Choi, ${ }^{\dagger}$ and Min Su Han \\ Department of Chemistry, Chung-Ang University, Seoul 156-756,Korea."E-mail: mshan@cau.ac.kr \\ ${ }^{\dagger}$ Department of Civil Engineering, Chungbuk National University, Cheongju-si, Chungbuk 361-763, Korea \\ Received September 30, 2010, Accepted October 26, 2010
}

Key Words: Adenosine triphosphate, Gold nanoparticle, Assay, Acetylcholinesterase

\begin{abstract}
Alzheimer's disease is a highly prevalent neurodegenerative disease that is characterized initially by the selective loss of cholinergic neurons in the basal forebrain. The loss of cholinergic cells, particularly in the basal forebrain, is accompanied by the loss of the neurotransmitter, acetylcholine. ${ }^{1}$ Acetylcholinesterase inhibitors form the basis of the newest drugs available for the management of this disease because this enzyme rapidly hydrolyzes the active neurotransmitter acetylcholine into inactive compounds, choline and acetic acid. ${ }^{2}$ These inhibitors can treat Alzheimer's disease by increasing the level of acetylcholine by blocking the activity of acetylcholinesterase. Many compounds have been synthesized by combinatorial chemistry to discover acetylcholinesterase inhibitors rapidly. ${ }^{3}$ Combinatorial chemistry enables to large libraries of compounds to be synthesized within a short time period, and the libraries of compounds have enabled the development of many potential acetylcholinesterase inhibitors as drugs for Alzheimer's disease. ${ }^{3,4}$ However, one of the bottlenecks in drug discovery is the selection of drug candidates from the many compounds in these libraries. ${ }^{5}$ To overcome this problem, high-throughput screening methods were used to screen large libraries of potential drug candidates. ${ }^{6}$ Previously, many high throughput screening compatible methods for acetylcholinesterase have been developed based on fluorescent dyes, chromogenic dyes, gold nanoparticles, silver nanoparticles, polymer, mass spectroscopy, high performance chromatography and thin layer chromatography. Among these methods, the most common is an organic dye based-method that involves the activation of an enzyme cascade, where acetylcholinesterase hydrolyses acetytholcholine to thiolcholine. The subsequent product produces a colorimetric product by reacting with thiol reactive chromogenic dyes, such as 5,5'-dithio-bis (2-nitrobenzoic acid) (DTNB or Ellman's reagent). ${ }^{8}$ Although the colorimetric method is used widely, the method suffers from low sensitivity, low signal/noise ratio and high background absorbance when used as a high throughput screen for a large size library. ${ }^{7 \mathrm{i}}$ As a result, other colorimetric high throughput screening methods of a library of acetylcholinesterase inhibitors are needed.
\end{abstract}

Gold nanoparticles (AuNPs) can be a good thiol reactivechromogeic dye for a thioester-based enzyme assay, such as acetylcholinesterase, because they have 3 - 5 orders of magnitude higher extinction coefficients than organic dye molecules. ${ }^{9}$ Moreover, when AuNPs are exposed to thiol, they aggregate immediately to induce a dramatic red to blue color change.
However, unmodified AuNPs, such as citric acid-caped AuNPs, are difficult to use in the real-time monitoring of the activity of the target enzyme because the AuNPs are quite sensitive to a range of factors, such as the electrolyte concentration, $\mathrm{pH}$ of the buffer and protein concentration. ${ }^{9}$ Therefore, a change in any of the abovementioned parameters results in irreversible aggregation of unmodified AuNPs as well as a significant red shift in the absorbance spectrum. Therefore, unmodified AuNPs are difficult to use for the real-time monitoring of the activity of the target enzyme. To solve these problems, the properties of ATP-stabilized gold nanoparticles (sAuNPs) were recently employed for the real-time monitoring of the activity of protease. ${ }^{10}$ The sAuNPs are stable in a buffer solution in the presence of high salt concentrations. However, the color of the sAuNPs solution changes immediately when exposed to the thiol produced by the target enzyme, which hydrolyzes the thioester bond on the substrate. In this paper, the strategy of the enzyme assay method was expanded to assay the activities of acetylcholinesterase and its inhibitors.

In this assay, sAuNPs and acetylthiocholine (1) were used. The thioester bond can be cleaved catalytically using acetylcholinesterase, and the hydrolyzed product (thiocholine) can react with sAuNPs. This process causes a change in the optical properties of the sAuNPs, and an assay of the enzyme activity becomes possible as Scheme 1. Firstly, the stability of the AuNPs stabilized with various concentrations of ATP was tested in the presence of 1 because the stability of sAuNPs to a thioester is quite sensitive to the ATP concentration. The sAuNPs are stable to acetythiocholine in the case of AuNPs stabilized with higher concentrations of $10 \mu \mathrm{M}$ ATP (see supplemental infor-

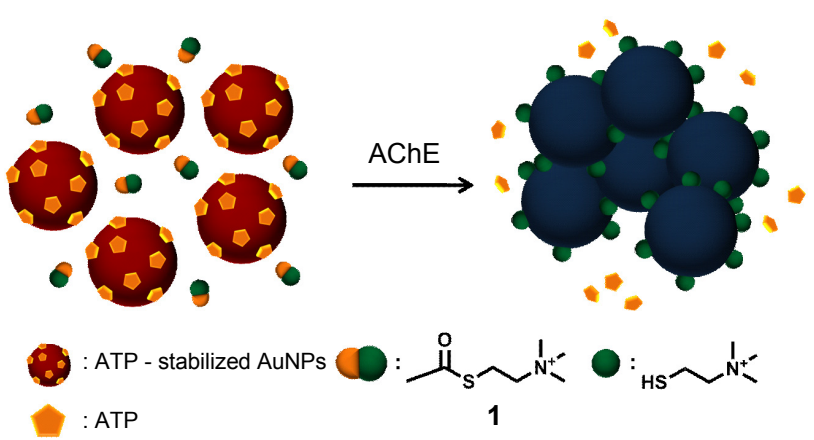

Scheme 1. Schematic diagram of the colorimetric acetycolinesterase assay 

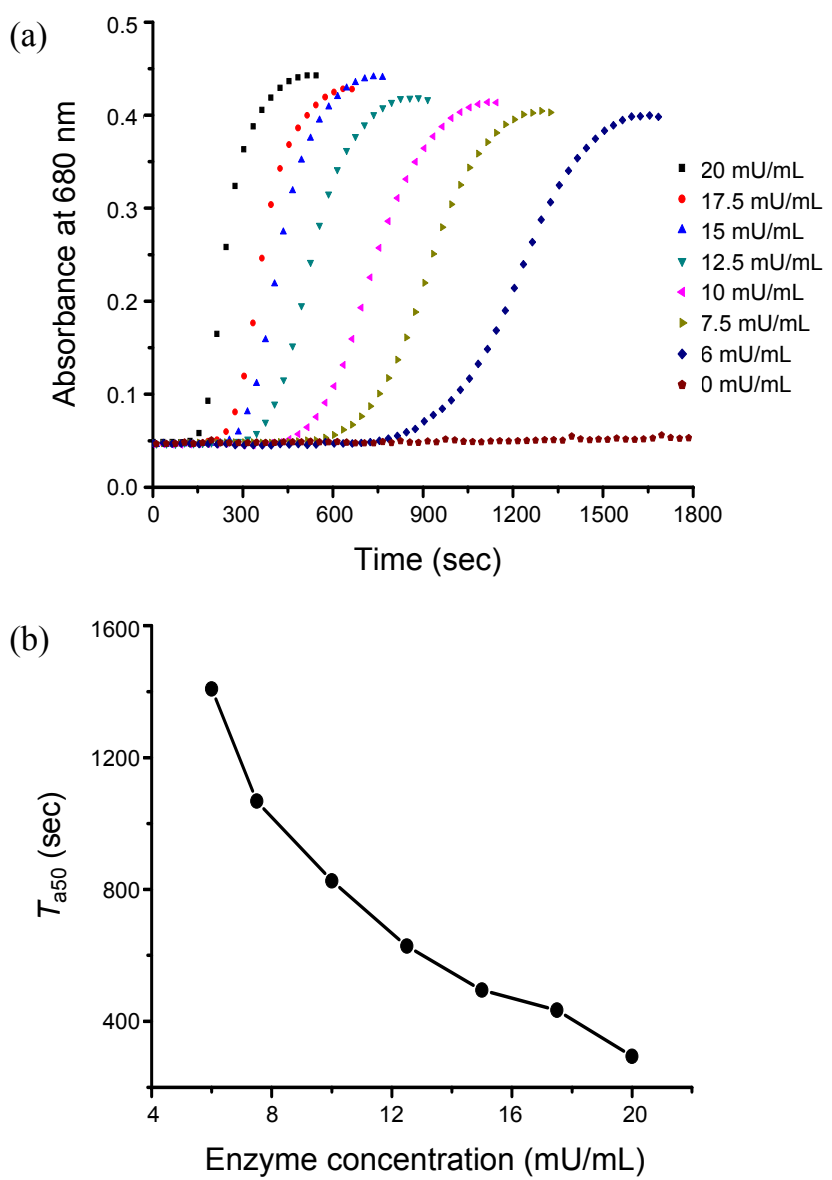

Figure 1. (a) Monitoring of the acetylcholinesterase-catalyzed hydrolysis of acetylthiocholine $(20 \mu \mathrm{M})$ to thiocholine at $\mathrm{pH} 7.0(10 \mathrm{mM}$ $\mathrm{SPB}+10 \mathrm{mM} \mathrm{NaCl})$ using the ATP stabilized AuNPs (3 nM). Hydrolysis was monitored at an extinction wavelength of $680 \mathrm{~nm}$. (b) Replot of $T_{\mathrm{a} 50}$ against the acetylcholinesterase concentrations $(0,6.0,7.5$, $10.0,12.5,15.0,17.5$, and $20.0 \mathrm{mU} / \mathrm{mL}$ )

mation). Therefore, the AuNPs stabilized by mixing ATP ( 20 $\mu \mathrm{M})$ with AuNPs (diameter: $13 \mathrm{~nm}$ ) combined with acetylthiocholine were utilized in this assay. A mixture of sAuNPs and $\mathbf{1}$ was used to evaluate the enzymatic activity of acetylcholinesterase. As acetylcholinesterase hydrolyzes 1, the sAuNPs are aggregated, generating a blue color due to the sAuNPs reacting with the hydrolyzed product (thiocholine). The color can be observed by the naked eye, or the absorbance $(680 \mathrm{~nm})$ can be measured by UV-vis spectroscopy. In a typical experiment, known concentrations of acetylcholinesterase were added to the assay mixture containing sAuNPs and $\mathbf{1}(10 \mu \mathrm{M})$ in a pH 7.0 buffer solution $(10 \mathrm{mM}$ sodium phosphate buffer $(\mathrm{SPB})+10$ $\mathrm{mM} \mathrm{NaCl}$ ). Upon hydrolysis of the thioester in $\mathbf{1}$ by acetylcholinesterase, the color of the sAuNPs solution changed dramatically from red to blue at a specific time. By measuring the absorbance of the solution at $680 \mathrm{~nm}$ (Figure 1), quantitative analysis of the acetylcholinesterase-catalyzed hydrolysis of $\mathbf{1}$ was carried out, and the reaction rate increased with increasing enzyme concentration. The kinetics of this assay showed unusual behavior in that the absorbance of the solution changed dramatically at a specific time, which may be due to the aggregation of sAuNPs when the surface of the AuNPs are modified

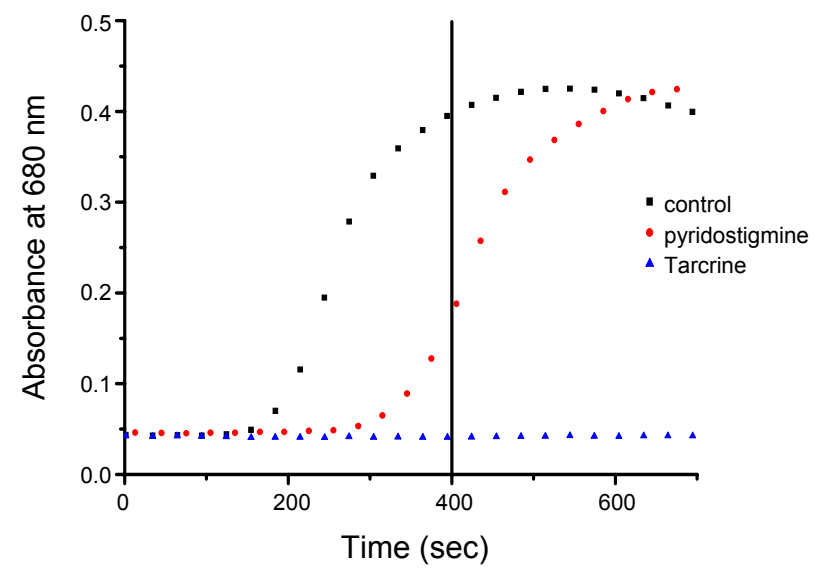

Figure 2. Determination of the relative activity of the acetycholinesterase inhibitors. Plot of the UV absorbance at $680 \mathrm{~nm}$ as a function of time. The increase in $T_{\text {a } 50}$ was caused by the addition of an acetycholinesterase inhibitor $(20 \mathrm{nM})$ to the $\mathrm{pH} 7.0$ buffer solution (10 $\mathrm{mM} \mathrm{SPB}+10 \mathrm{mM} \mathrm{NaCl}$; ATP $20 \mu \mathrm{M}$ ) containing acethylthiocholine (1) $(20 \mu \mathrm{M})$, acetycholinesterase $(20 \mathrm{mU} / \mathrm{mL})$, and ATP stabilized AuNPs (3 nM).

with thiocholine beyond a certain point. Therefore, unlike a thiol reactive organic dye based-acetylcholinesterase assays, the kinetic parameters in an acetylcholinesterase assay and its inhibitor assay, such as $\mathrm{IC}_{50}$ and $K_{\text {cat }}$, could not be analyzed using this assay. Although this assay could not analyze the kinetic parameters, this method can has several advantages in screening a large size library compared to previous colorimetric acetylcholinesterase assays, such as the wildly used Ellman reagent based-assay. This method is more sensitive than the Ellman reagent based assay. ${ }^{11}$ A high throughput assay (HTS) format based on the UV-vis detection of Ellman reagent is problematic for HTS because the screening libraries often contain compounds that absorb strongly at $412 \mathrm{~nm}$. However, this method can be free of these problems because it monitors the activity of acetylcholinesterase by measuring the absorbance of sAuNPs at $680 \mathrm{~nm}$. In particular, because the absorbance of the assay solution changed dramatically at a specific time (Figure 1a), the unusual kinetic behavior in this assay enhances the signal/noise ratio when a large size library of acetylcholinesterase inhibitors is screened using the end-point method.

To demonstrate the advantage of this assay, the proposed assay was used to evaluate the relative activity of the acetylcholinesterase inhibitors. In a typical assay, acetycholinesterase was added to a control solution and to the assay solutions containing one of the following acetylcholinesterase inhibitors: tarcrine, and pyridostigmined. ${ }^{12}$ The inhibitor activity was monitored at $680 \mathrm{~nm}$ as a function of time (sample scan rate: $30 \mathrm{~s}^{-1}$ ). As shown in Figure 2, the absorbance changed over a very narrow time range, and the time at which the absorbance of the assay solution shows a $50 \%$ change $\left(T_{\text {a } 50}\right)$ can be used as a parameter of inhibition. The inhibitors decrease the acetylcholinesterase activity, and increase the $T_{\mathrm{a} 50}$, and hence, the corresponding time required for a solution color change. The inhibitors studied exhibited the following trend in the $T_{\text {a50 }}$ values: tarcrine $>$ pyridostigmined $>$ control (Figure 2). This order is consistent with the activities of the inhibitors to acetylcholinesterase re- 
ported in the literature. ${ }^{12}$ In particular, at a specific time, sharp absorbance changes enable the selection of clearly more potent inhibitors than a specific inhibitor in a library. For example, at 400 seconds, compared to the absorbance of the assay solution containing pyridostigmine, the absorbance of the control assay solutions and the solution containing tacrine was $>0.2$ and $<$ 0.15 , respectively. Therefore, tacrine was found to be a more potent inhibitor than pyridostigmine by measuring the off/on signals at a specific time. The property in this assay can be very useful for end-point analysis.

In conclusion, a new colorimetric assay for screening the acetycholinesterase activity and for determining the relative inhibitory activity of the acetycholinesterase inhibitors was developed using a mixture of $\mathbf{1}$ and sAuNPs. This method is more sensitive than the widely used Ellman reagent basedcolorimetric assay. In particular, with this screening method, a dramatic color change occurs over a very narrow time range, which enables the activities of acetycholinesterase inhibitors to be discriminated easily with high signal/noise ratios in an end-point assay.

\section{Experimental Section}

Chemicals. All chemicals used were of analytical grade or of the highest purity available. Chloroauric acid $\left(\mathrm{HAuCl}_{4} \cdot 3 \mathrm{H}_{2} \mathrm{O}\right)$, citric acid, tarcrine, pyridostigmined, and acetycholinesterase (from Electrophorus electricus) were purchased from Sigma Aldrich (USA). All glassware was cleaned thoroughly with freshly prepared aqua regia $\left(3: 1(\mathrm{v} / \mathrm{v}) \mathrm{HCl} / \mathrm{HNO}_{3}\right)$ and rinsed thoroughly with Milli-Q water prior to use. Milli-Q water was used to prepare all the solutions in this study.

Preparation of AuNPs. All glassware was washed with freshly prepared aqua regia $\left(3: 1=\mathrm{HCl}: \mathrm{HNO}_{3}\right)$ followed by extensive rinsing with doubly distilled $\mathrm{H}_{2} \mathrm{O}$. Citric acid stabilized $\mathrm{Au}$ particles with a diameter of $13 \mathrm{~nm}$ were prepared by adding 50 $\mathrm{mL}$ of a citrate solution $(38.8 \mathrm{mM})$ to $500 \mathrm{~mL}$ of boiling $1.0 \mathrm{mM}$ $\mathrm{HAuCl}_{4} \cdot 3 \mathrm{H}_{2} \mathrm{O}$ with vigorous stirring. After the appearance of a deep red color, boiling and stirring were continued for $15 \mathrm{~min}$.

Colorimetric Screening Assay. AuNPs (diameter: $13 \mathrm{~nm}$; $3 \mathrm{nM})$ were mixed with ATP $(20 \mu \mathrm{M})$ and stabilized by incubation in distilled water. After incubation for $5 \mathrm{~min}$, the concentration of the mixture was adjusted using $10 \mathrm{mM}$ sodium phosphate buffer ( $\mathrm{pH} 7.0,10 \mathrm{mM} \mathrm{NaCl})$ and acetylthiocholine (20 $\mu \mathrm{M})$ so that the final concentration of the AuNPs and ATP were $3 \mathrm{nM}$ and $20 \mu \mathrm{M}$, respectively. The assay was initiated by adding acetycholinesterase from Electrophorus electricus $(20 \mathrm{mU} / \mathrm{mL})$ to the assay mixture, and the hydrolysis kinetics were monitored by UV-vis spectroscopy at the extinction wavelength of $680 \mathrm{~nm}$. The solution was continuously stirred at room temperature with a magnetic stir bar to ensure homogeneity.

Acknowledgments. This study was supported by National Research Foundation of Korea Grant funded by the Korean Government (2009-0071807) and Priority Research Centers Program through the National Research Foundation of Korea
(NRF) funded by the Ministry of Education, Science and Technology (2009-0093817).

\section{References and Notes}

1. Whitehouse, P. J.; Price, D. L.; Struble, R. G.; Clark, A. W.; Coyle, J. T.; Delong, M. R. Science 1982, 215, 1237-1239.

2. (a) Francotte, P.; Graindorge, E.; Boverie, S.; de Tullio, P.; Pirotte, B. Curr. Med. Chem. 2004, 11, 1757-1778. (b) Ibach, B.; Haen, E. Curr. Pharm. Des. 2004, 10, 231-251. (c) Parihar, M. S.; Hemnani, T. J. Clin. Neurosci. 2004, 11, 456-467.

3. (a) Ansari, F. L.; Iftikhar, F.; Ihsan-Ul-Haq; Mirza, B.; Baseer, M.; Rashid, U. Bioorg. Med. Chem. 2008, 16, 7691-7697. (b) Bunyapaiboonsri, T.; Ramström, O.; Lohmann, S.; Lehn, J.-M.; Peng, L.; Goeldner, M. ChemBioChem 2001, 2, 438-444. (c) Mulcahy, S. P.; Li, S.; Korn, R.; Xie, X.; Meggers, E. Inorg. Chem. 2008, 47, 5030-5032. (d) Krasiński, A.; Radić, Z.; Manetsch, R.; Raushel, J.; Taylor, P.; Sharpless, K. B.; Kolb, H. C. J. Am. Chem. Soc. 2005, 127, 6686-6692. (e) Recanatini, M.; Cavalli, A.; Belluti, F.; Piazzi, L.; Rampa, A.; Bisi, A.; Gobbi, S.; Valenti, P.; Andrisano, V.; Bartolini, M.; Cavrini, V. J. Med. Chem. 2000, 43, 2007-2018. (f) Kapková, P.; Heller, E.; Unger, M.; Folkers, G.; Holzgrabe, U. J. Med. Chem. 2005, 48, 7496-7499. (g) Fallarero, A.; Oinonen, P.; Gupta, S.; Blom, P.; Galkin, A.; Mohan, C. G.; Vuorela, P. M. Pharmacol. Res. 2008, 58, 215-221. (h) Scheck, M.; Koch, M. A.; Waldmann, H. Tetrahedron 2008, 64, 4792-4802.

4. (a) Thompson, L. A.; Ellman, J. A. Chem. Rev. 1996, 96, 555-600. (b) Balkenhohl. F.; von dem Bussche-Hünnefeld, C.; Lansky, A.; Zechel, C. Angew. Chem. Int. Ed. Engl. 1996, 35, 2288-2337.

5. Walker, M. J. A.; Barrett, T.; Guppy, L. J. Drug Discov. Today: Targets 2004, 3, 208-215.

6. (a) Johnston, P. A.; Johnston, P. A. Drug Discov. Today 2002, 7, 353-363. (b) Boger, D. L.; Desharnais, J.; Capps, K. Angew. Chem. Int. Ed. 2003, 42, 4138-4176. (c) Wang, S.; Sim, T. B.; Kim, Y.-S.; Chang, Y.-T. Curr. Opin. Chem. Biol. 2004, 8, 371-377.

7. (a) Maeda, H.; Matsuno, H.; Ushida, M.; Katayama, K.; Saeki, K.; Itoh, N. Angew. Chem. Int. Ed. 2005, 44, 2922-2925. (b) Wang, M.; Gu, X.; Zhang, G.; Zhang, D.; Zhu, D. Anal. Chem. 2009, 81, 4444-4449. (c) Zhu, J.; Dhimitruka, I.; Pei, D. Org. Lett. 2004, 6, 3809-3812. (d) Grassetti, D. R.; Murray, J. F., Jr. Arch. Biochem. Biophys. 1967, 119, 41-49. (e) Wang, M.; Gu, X.; Zhang, G.; Zhang, D.; Zhu, D. Langmuir 2009, 25, 2504-2507. (f) Pavlov, V.; Xiao, Y.; Willner, I. Nano Lett. 2005, 5, 649-653. (g) Virel, A.; Saa, L.; Pavlov, V. Anal. Chem. 2009, 81, 268-272. (h) Feng, F.; Tang, Y.; Wang, S.; Li, Y.; Zhu, D. Angew. Chem. Int. Ed. 2007, 46, 78827886. (i) Xu, Z.; Yao, S.; Wei, Y.; Zhou, J.; Zhang, L.; Wang, C.; Guo, Y.J. Am. Soc. Mass Spectrom. 2008, 19, 1849-1855. (j) de Jong, C. F.; Derks, R. J. E.; Bruyneel, B.; Niessen, W.; Irth, H. J. Chromatogr. A 2006, 1112, 303-310. (k) Zheng, X.-Y.; Zhang, Z.-J.; Chou, G.-X.; Wu, T.; Cheng, X.-M.; Wang, C.-H.; Wang, Z.-T. Arch. Pharm. Res. 2009, 32, 1245-1251.

8. Ellman, G. L.; Courtney, K. D.; Andres, V., Jr.; Feather-Stone, R. M. Biochem. Pharmacol. 1961, 7, 88-95.

9. (a) Stewart, M. E.; Anderton, C. R.; Thompson, L. B.; Maria, J.; Gray, S. K.; Rogers, J. A.; Nuzzo, R. G. Chem. Rev. 2008, 108, 494521. (b) Ghosh, S. K.; Pal, T. Chem. Rev. 2007, 107, 4797-4862. (c) Burda, C.; Chen, X.; Narayanan, R.; El-Sayed, M. A. Chem. Rev. 2005, 105, 1025-1102. (d) Rosi, N. L.; Mirkin, C. A. Chem. Rev. 2005, 105, 1547-1562.

10. Kim, M. H.; Lee, S. S.; Chung, S. J.; Jang, H. H.; Yi, S.; Kim, S.; Chang, S.-K.; Han, M. S. Tetrahedron Lett. 2010, 51, 2228-2231.

11. Rhee, K.; van de Meent, M.; Ingkaninan, K.; Verpoorte, R. J. Chromatogr. A 2001, 915, 217-223.

12. Arnal, F.; Coté, L. J.; Ginsburg, S.; Lawrence, G. D.; Naini, A.; Sano, M. Neurochem. Res. 1990, 15, 587-591.Ling, R.; Yoshida, M.; Mariano, P. S. J. Org. Chem. 1996, 61, 4439-4449. 